\title{
IMPLEMENTACIJA PAMETNOG SISTEMA U PROJEKAT STAMBENE JEDINICE ZA SLEPU OSOBU
}

\section{IMPLEMENTATION OF A SMART SYSTEM IN DESIGN OF DWELLING UNIT FOR THE BLIND}

\section{Renata Sejdija, Fakultet tehničkih nauka, Novi Sad}

\section{Oblast - ARHITEKTURA}

Kratak sadržaj - Ovaj rad se bavi istraživanjem $i$ analizom problema i ograničenja, sa kojima se susreću osobe bez čula vida, kao i posledicama gubitka vida. Istraživanje treba da doprinese svest o poboljšanju kvaliteta života osobama sa invaliditetom. Upravo je to $i$ cilj projekta, koji je postignut tako što se pametna tehnologija uvela u stambenu jedinicu. Na taj način, stvorio se jedan nezavisan život, jer je i osnovna funkcija ovog stambenog prostora da poveća stepen slobode.

Ključne reči: Stambena jedinica, posledice gubitka vida, pametna tehnologija

\begin{abstract}
This paper deals with the research and analysis of problems and limitations, which are encountered by people without the sense of sight, as well as the consequences of vision loss. Research should contribute to awareness of improving the quality of life of people with disabilities. This is exactly the goal of the project, which was achieved by introducing smart technology into the dwelling unit. In that way, an independent life was created, because the basic function of this living space is to increase the degree of freedom.
\end{abstract}

Keywords: Dwelling unit, vision loss consequences, smart system

\section{UVOD}

Arhitektura, kao delatnost koja se bavi artikulacijom prostornih elemenata, bi prvenstveno trebala da se vodi svešću o univerzalnom. Ono što je u okviru ovog rada i što definiše univerzalni dizajn jeste prostor koji zadovoljava potrebe svih ljudi, mladih i starih, sposobnih i onesposobljenih. Kako je ovde reč o osobama oštećenog vida pojam slobode dominira, dok je pojam lepote ostavljen po strani.

Glavno polazište istraživanja bazira se na analizi osnovnih pojmova vezanih za oštećenje vida kao i na analizi posledica gubitka vida, sve do istraživanja vezana za pametne kuće. Jedan od načina da se kvalitet života poboljša jeste da se životno okruženje napravi udobnijim mestom za življenje, a u okviru ovog rada, to je postignuto uvodeći pametnu tehnologiju u stambenu jedinicu kako bi se omogućio nezavisan život.

\section{NAPOMENA:}

Ovaj rad proistekao je iz master rada čiji mentor je bila dr Jelena Atanacković Jeličić, red. prof.

\section{OSNOVNI POJMOVI VEZANI ZA OŠTEĆENJE I GUBITAK VIDA}

Oštećenje vida je sveobuhvatan izraz koji uključuje ljude sa bilo kakvim vizuelnim deficitom. Nastaje kao posledica očnih bolesti, uređenog stanja ili stečenog stanja. Generalno govoreći, oštećenje može da varira od manjih problema sa vidom do potpunog slepila. Slepe osobe karakteriše ograničena sloboda kretanja i izvesna bespomoćnost u prostoru, a naročito u onom nepoznatom, dok će osoba sa slabim vidom možda moći da vidi, ne samo svetlost, već i boje i oblike.

Njihov vid je nejasan i maglovit, što je možda i opasnije od potpunog slepila, jer dovodi do ishitrenih radnji poput pretrčavanja puta zbog loše procene boje na semaforu, što nikako nije u koleraciji sa sigurnošću.

\subsection{Posledice gubitka vida na praktično funkcionisanje}

Ograničenja imaju visok uticaj na osobu oštećenog vida i odražavaju se, pre svega, na njeno praktično funkcionisanje. Sposobnost brige o sebi i sopstvenom domaćinstvu je ključna komponenta za sposobnost samostalnog življenja i jedna od prvih prepreka. Za prevazilaženje ove prepreke uče se razne tehnike svakodnevne brige o sebi, što doprinosi razvijanju sposobnosti i samostalnosti.

Jedna od najznačajnijih posledica gubitka vida je sposobnost kretanja kroz fizički i socijalni prostor. Slepi i slabovidi, uče o svom okruženju kroz interakciju sa njim, kroz pokrete, istraživanje, manipulisanje predmetima. Najveći broj slepih koristi štap, kao pomagalo za samostalno kretanje koje detektuje prepreke na putu. Još neke od posledica gubitka vida su sposobnost čitanja i pisanja, kao i uspeh u zapošljavanju koji je sveden na minimum [1].

\subsection{Posledice gubitka vida na socijalno funkcionisanje}

Priznavanje prava da se živi u zajednici, u kojoj su svi ljudi rođeni jednaki, omogućava da ljudi žive punim životom u društvu. To pravo se krši kada ljudi sa invaliditetom ne dobiju povratnu reakciju u vidu podrške u svakodnevnom životu, što dovodi do odricanja života $u$ zajednici. Osoba postaje svesna svog nedostatka vida jedino kao posledice društvenog ponašanja. Mišljenje o slepima kao osobama koje su nesrećne, sa pregršt ograničenim sposobnostima stvara duboku nelagodu kod slepih. Ovakav stav poprilično komplikuje uključenje slabovidih i slepih u različite sfere života, što dovodi do potcenjivanja u društvu [1]. 


\section{ANALIZA POSTOJEĆIH USLOVA STANOVANJA OSOBA BEZ VIDA}

Nedovoljna svest o univerzalnom dizajnu stvara prepreke, kako u urbanom prostoru, tako i okviru prostora namenjenom stanovanju. Svi mi imamo posebne potrebe, samo neki od nas imaju invaliditet. Iste potrebe se zadovoljavaju na različite načine. I osoba oštećenog vida takođe želi živeti u lepo uređenim i kvalitetnim kućama, ali im je potreban prostor koji je prilagođen njihovom načinu kretanja.

Kao relevantni ulazni podaci pri definisanju potreba korisnika prostora, uzeti su rezultati ankete sprovedenih 31. marta 2021. godine. Ispitanici su deo Saveza slepih Srbije. Anketa je sadržala pitanja vezana za podatke o trenutnim karakteristikama stambenih jedinica ispitanika, kao i ona koja se tiču predloga za poboljšanje uslova stanovanja.

Kada je u pitanju struktura domaćinstva, zabeležene su osobe koje žive same i osobe u bračnoj zajednici. Ovaj podatak je značajan zbog postojanja predrasuda da osobe bez vida nisu sposobne da žive same i da samostalno obavljaju sve neophodne funkcije.

$\mathrm{Na}$ pitanje o definisanju pojma prepreke, odgovori su se odnosili na definisanje prepreke kao bilo kog elementa $\mathrm{u}$ prostoru koji je neočekivan ili nov, a kada je reč o orijentaciji, $u$ većini slučajeva se zasniva na pamćenju ako se radi o prostoru koji je korišćen.

Odgovori na pitanja sadrže i podatke o uticaju zvučnih karakteristika i predlozima za poboljšanje funkcionalnosti stambenog prostora, dok se za predlog boljeg kvaliteta života može naići na termin pametne kuće.

\section{ODNOS ARHITEKTONSKOG PROSTORA I SENZORNIH SISTEMA}

Naše senzorno iskustvo uključuje niz čula, među kojima su čulo vida, sluha, mirisa, ukusa i dodira. Međurim, uglavnom se oslanjamo na čulo vida, dok su ostala čula stavljena u drugi plan [2].

Arhitektonski prostori su u svom eteričnom obliku zapravo mirisi, osećaji, druženja i uspomene. Sećanja na ljude s kojima smo u njima boravili, takođe je jedan od doživljaja prostora.

Pamtimo ih po oblicima, bojama, vizurama, atmosferi, smehu ili tuzi. Pamtimo ih po autentičnosti doživljaja. Neki pamte u odnosu na vizuelno iskustvo, a neko na dublji način koji otkriva sve druge prostorne kvalitete.

$\mathrm{U}$ kontekstu ovog rada, u kojem vizuelno iskustvo ostavljamo po strani, sva druga čula su shvaćena kao alati za „,̌itanje“" prostora. Čulo mirisa, ukusa, sluha i dodira su sredstva putem kojeg osobe sa oštećenim vidom doživljavaju prostor.

U tom slučaju njihov opažaj neće biti manje precizan od onog koji imaju osobe koje vide. Razlog tome jeste prilagođavanje nedostatku ili gubitku čula tako što se intenzivnije koriste ostali funkcionalni čulni modaliteti.

Bez obzira na to o kakvom je prostoru reč, oni se u naše sećanje upisuju duboko i trajno, i nalaze se u podsvesti i čekaju neki okidač koji će ih čudom vratiti u naše misli u punom sjaju trenutka u kojem smo u njima već boravili.

\section{PERCEPCIJA PROSTORA OSOBA BEZ VIDA}

Intenzivnim korišćenjem ostalih čula, osobe sa invaliditetom povećavaju njihovu efikasnost u izvođenju radnji, što može rezultirati i poboljšanjem perceptivnih veština.

Slušna percepcija je od velike važnosti za slepe osobe, jer im omogućava pristup informacijama iz neposredne stvarnosti, kao što im pomaže pri prostornoj orijentaciji. Putem slušanja slepe osobe raspoznaju ljudske glasove, brojne šumove, svakodnevne aktivnosti, buku i druge zvukove koji im pomažu u svakodnevnoj interakciji sa okolinom.Važan segment slušanja je prostorna orijentacija, koja služi za lokalizaciju izvora zvuka i na taj način omogućava slepim osobama stvaranje vizije o prostoru u kojem se nalaze.

Drugi oblik percipiranja je taktilno percipiranje. Dodir takođe spada među najvažnije senzore kojima slepe osobe uspostavljaju odnos sa stvarnošću. Omogućava im spoznavanje oblika različitih predmeta, svojstva površine predmeta, a sa vremenom uče prepoznati i različite građe materijala, debljinu, dubinu i težinu predmeta, prostorne odnose unutar predmeta i među različitim predmetima. Značajna razlika između vidne $\mathrm{i}$ taktilne percepcije je $\mathrm{u}$ svesnosti čoveka prilikom stvaranja percepcije. Obe percepcije su aktivni procesi, ali pri stvaranju vidnih percepcija osoba ne ulaže poseban napor, ona vizuelno opaža i bez svesne namere. Dok je taktilna percepcija svestan i nameran proces.

\section{DEFINICIJA PAMETNE KUĆE}

Danas skoro da ne postoji osoba koja kod sebe nema neki od pametnih uređaja. Došli smo do tog nivoa gde svako može svoj život uređivati preko određenih uređaja. Postalo je previše lako i ljudi se sve više oslanjaju na pametne uređaje. Neko ovo posmatra kao opasnost, a neko vidi poboljšanje kvaliteta modernog života.

Svima je poznato da oznaku „smart“ imaju telefoni, televizori i satovi. Pored ovih šire poznatih, postoji i mnogo drugih pametnih uređaja za domaćinstvo koji na razne načine mogu doprineti da pojednostavimo i olakšamo svakodnevno funkcionisanje.

Pametne kuće imaju ugrađene različite vrste senzora koji su povezani sa pametnim uređajima u domaćinstvu $u$ poseban sistem. Sistemom se može upravljati na različite načine, a sve u skladu sa potrebama i navikama korisnika tog prostora. Ono što izdvaja obične kuće od pametnih jeste što se ove kuće mogu inteligentno uključiti u razne interakcije sa svojim stanovnicima i tako im omogućavaju udobnost i siguran život [3].

Koliko je samo idealan za osobe bez ikakvog oštećenja čula, toliko ovaj sistem pojednostavljuje već dovoljno otežan način življenja osobama oštećenog vida.

\section{DEFINISANJE KORISNIKA PROSTORA}

Korisnik je u ovom slučaju osoba bez vida, koja je vid izgubila po rođenju. Predviđeno je da osoba živi sa partnerom, što je povezano sa težnjom za formiranje prostora univerzalnog dizajna. 
Fokus je, pre svega, na osobi bez vida, dok osoba sa vidom razbija predrasude o tome da stambena jedinica treba da bude posebno prilagođena isključivo i samo osobama bez vida, ukoliko se za njih projektuje.

U ovom slučaju, osoba sa nedostatkom vida je žena starosti 42 godine. Profesija osobe je značajna jer predstavlja jedan od faktora koji utiču na definisanje potrebnih funkcionalnih zona, a reč je o radnom prostoru gde bi korisnik razvijao svoje profesionalne sposobnosti.

Navike korisnika prostora su najčešće aktivnosti koje se dešavaju pre i nakon radnog vremena i koje se zapravo odnose na korišćenje prostora u okviru stambene jedinice.

\section{ARHITEKTONSKI PROJEKAT STAMBENE JEDINICE}

Predmet praktičnog dela rada predstavlja projekat idejnog rešenja enterijera stambene jednice za slepu osobu. Glavni fokus projekta jeste dizajn enterijera, prethodno istraženog u skladu sa temom rada, kao i implementacija pametnog sistema.

Projekat stambene jedinice čini prizemni objekat, iz razloga jednostavnog pristupa bez savladavanja visinskih razlika. U ovom arhitektonskom projektu naglašena su čula sledećim redosledom: dodir, sluh, miris, ukus. U svakom prostoru jedno od ovih čula naglašeno je i predstavljeno na različite načine, a najčešće materijalom. Glavni fokus u radu bio na orijentaciji.

$\mathrm{Da}$ bi se olakšalo kretanje i izbegle potencijalne opasnosti, kuća nema unutrašnja vrata, osim u kupatilima, a takođe nema i pragove, što korisniku olakšava prostorni kontinuitet.

Osim toga, raspored u novoprojektovanoj stambenoj jedinici, na neki način, prati staru šemu, koja je poznata korisniku, ali je samo proširena sa dodatnim prostorijama koje su predstavljale nedostatke u postojećoj varijanti.

Da bi se efekat lavirinta sveo na minimum, stvoren je hodnik iz kojeg se ulazi u sve ostale prostorije (videti sliku 1). Cilj je bio da se stvori što jednostavniji i razumljiviji prostor.

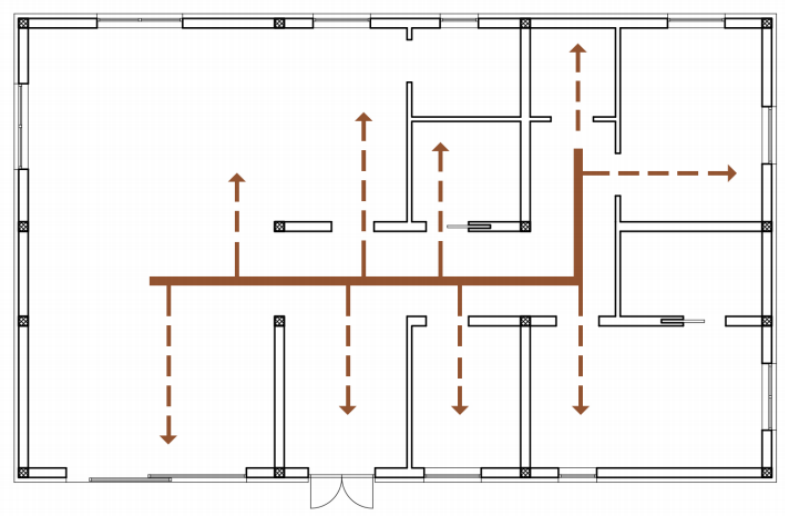

Slika 1. Analiza kretanja

U skladu sa mogućim rutama kretanja, stvorene su informativni taktilni markeri, koji su integrisani $\mathrm{u}$ pod (videti sliku 2). One imaju zadatak da obaveste korisnika na prepreku i granicu, putem dodira. Prepreku predstavlja svaki element koji je neočekivan, a granicu predstavlja svest o promeni prostorije.

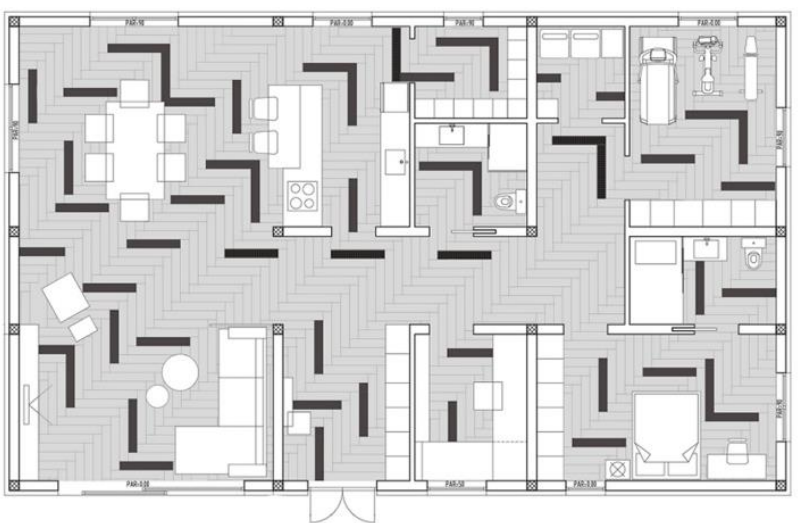

Slika 2. Integrisanje taktilnih markera u popločanje

Da bi se ploče lakše prepoznale, upotrebljene su teksture koje koje se međusobno znatno razlikuju na dodir, a to su drvo i kamen.

Marker koji daje informaciju o prepreci nema karakterističnu površinsku šaru već samo poseduje teksturu kamena, dok se kod markera koji daje informaciju o granici pojavljuje površinska šara u obliku konveksnih tačaka koju slepa osoba identifikuje pomoću svojih stopala (videti sliku 3). Ukoliko korisnik stoji paralelno sa taktilnim markerom, on ga obaveštava da se ispred ili iza nalazi prepreka ili druga prostorija.

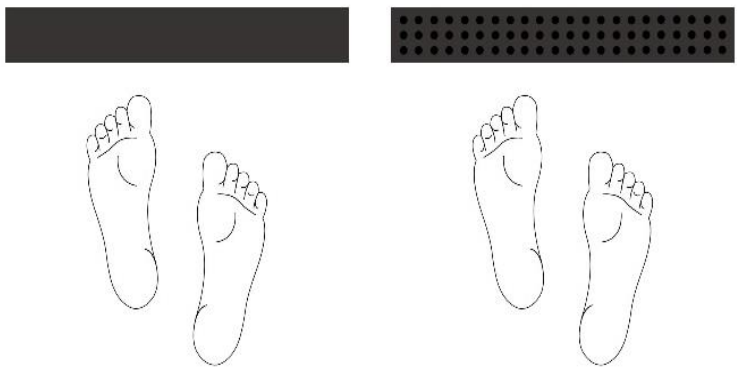

Slika 3. Prepreka i granica

Pored orijentira putem dodira, prisutan je i orijentir putem zvuka, odnosno sluha. Tako je u dnevnoj sobi prisutan televizor, koji služi kao orijentir da se korisnik približava zidu. Zatim, postoji ozvučenje u prostoriji za teretanu, za efikasnije vežbanje, i ono se pali samo po unapred predviđenom terminu za vežbanje.

Moguće je orijentisati se i uz pomoć čula mirisa. Tako kad korisnik zakorači iz hodnika u kuhinju osetiće aromu začina, dok će u spavaćoj sobi sa kupatilom osetiti miris lavande, za koju je dokazano da pročišćava telo i um.

\section{SCENARIO PAMETNE KUĆE}

U sklopu ovog projekta formirana su tri scenarija u skladu sa navikama korisnika i u skladu sa smanjenjem rizika. Prvi i treći scenario je formiran u zavisnosti od navika, dok se drugi scenario aktivira u slučajevima opasnosti kada korisnici nisu kod kuće.

Sva tri scenarija su memorisana i svakodnevno se ponavljaju, ali uvek postoji mogućnost njihovih izmena.

\subsection{Prvi scenario}

Prvi scenario je formiran $u$ odnosu na jutarnje navike korisnika. Aktivira se u pet sati ujutru, kada korisnik 
ustaje zbog pripreme za posao, i započinje podizanjem električnih roletni. Pri odlasku do kupatila, aktivira se kafe aparat u kuhinji, a pri izlasku korisnika čeka spremna kafa za ispijanje. Putem mobilne aplikacije korisnik dobija informaciju, glasovnim putem, šta se trenutno nalazi u frižideru i šta nedostaje. Pre završavanja poslednjih priprema za posao, automatski se aktivira televizor, tako da korisnik uspe da odsluša jutarnji program pre odlaska.

Uzimajući u obzir da oba korisnika izlaze iz kuće u isto vreme, televizor se automatski gasi, roletne se automatski spuštaju, svetlo se automatski gasi, a kuća se automatski zaključava.

\subsection{Drugi scenario}

Nakon što su oba korisnika van kuće, postoji mogućnost automatske aktivacije drugog scenarija samo u slučajevima opasnosti. U slučaju alarma, korisnik će dobiti obaveštenje na svoj mobilni telefon, u kojoj će mu kuća govornim porukama opisati šta se dogodilo, na primer „alarm-provala-spavaća soba“ [4]. Takođe, automatskim zaključavanjem kuće, korisnici ne treba da vode računa o tome da li su isključili ringlu na šporetu, peglu, osvetljenje i slično, već se taj scenario sam pokreće. Tako u slučaju poplave, automatski bi se zatvorio glavni ventil za vodu, kao i glavno napajanje električnom energijom, čime bi se smanjila mogućnost negativnih posledica, što isto važi i u slučaju požara.

\subsection{Treći scenario}

Treči scenario je formiran $\mathrm{u}$ odnosu na popodnevne navike, nakon što se korisnici vrate sa posla. U određeno vreme je podešeno podizanje roletni i aktiviranje osvetljenja.

Tek pri ulasku u kuću, aktivira se aparat za kafu i rerna koju je potrebno zagrejati pre upotrebe. Takođe, nakon nekog izvesnog vremena aktiviraju se zvučnici u prostoriji koja je namenjena za teretanu, kako bi korisnika muzika podstakla na motivaciju za trening.

Korisnik u odnosu na taj zvuk dobija i informaciju o vremenu. Nakon što padne mrak, roletne se spuštaju, a osvetljenje se aktivira u odnosu na to u kojoj prostoriji se boravi, zahvaljujući senzoru pokreta.

\section{ZAKLJUČAK}

$\mathrm{Na}$ osnovu razmatranja navedene problematike može se zaključiti da pametne kuće ne doprinose samo većoj efikasnosti i povećanju udobnosti ljudi, nego doprinose i povećanju bezbednosti ljudi i materijalnih dobara, jer koriste napredne sisteme obezbeđivanja, sigurnosne kamere i brave, razne senzore $\mathrm{i}$ alarme kako bi prostor koji obuhvataju učinili sigurnijim, što je i vrlo bitno kada je reč o osobama sa invaliditetom.

Postavlja se pitanje da li je naša percepcija stvarno rezultat naših čula, pre svega vida, i da li osobe sa oštećenim vidom zaista mogu razumeti svet oko sebe. Naša verovanja na način kako nešto opažamo ne moraju biti istinita i opravdana. Shodno tome, ne može se reći da je znanje koje stiču osobe sa oštećenim vidom veće ili manje u odnosu na osobe bez oštećenja.

\section{LITERATURA}

[1] Žuvela, Biljana, 2013. ,Individualni i kontekstualni činioci zapošljavanja slepih i slabovidih osoba“, doktorska disertacija, Odeljenje za psihologiju, Filozofski fakultet, Beograd: Univerzitet u Beogradu

[2] Pallasmaa, Juhani. 2005. ,, The Eyes of the Skin “. Chichester: Wiley-Academy

[3] https://www.tehnomanija.rs/blog/superdomacinstvo/pametne -kuce/

[4] Nenad Četić, "Model bežičnih akustičkih senzora za komandovanje glasom u pametnim kućama", doktorska disertacija, Novi Sad, 2019.

\section{Kratka biografija:}

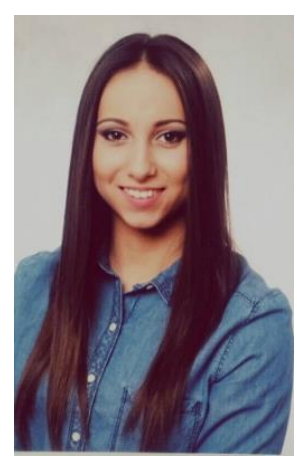

Renata Sejdija rođena je u Vrbasu 1996. godine. Master rad odbranila je 2021. godine na Fakultetu tehničkih nauka sa temom "Implementacija pametnog sistema $u$ projekat stambene jedinice $z a$ slepu osobu" pod mentorstvom prof. dr Jelene Atanacković Jeličić.

kontakt: sejdijarenata4@gmail.com 